\title{
AARHUS UNIVERSITY
}

\section{Coversheet}

This is the accepted manuscript (post-print version) of the article.

Contentwise, the accepted manuscript version is identical to the final published version, but there may be differences in typography and layout.

\section{How to cite this publication}

Please cite the final published version:

Dipankar Saha, Espen D. Bøjesen, Aref Hasen Mamakhel, Martin Bremholm, Bo B. Iversen (2017). In Situ PDF Study of the Nucleation and Growth of Intermetallic PtPb Nanocrystals. In ChemNanoMat, 3, 472 -478 DOI: https://doi.org/10.1002/cnma.201700069

\section{Publication metadata}

Title:

Author(s):

Journal:

DOI/Link:

Document version:
In Situ PDF Study of the Nucleation and Growth of Intermetallic PtPb Nanocrystals

Dipankar Saha, Espen D. Bøjesen, Aref Hasen Mamakhel, Martin Bremholm, Bo B. Iversen

ChemNanoMat

https://doi.org/10.1002/cnma.201700069

Accepted manuscript (post-print)

(C) The authors 2017. This is the peer reviewed version of the following article: Dipankar Saha, Espen D. Bøjesen, Aref Hasen Mamakhel, Martin Bremholm, Bo B. Iversen (2017). In Situ PDF Study of the Nucleation and Growth of Intermetallic PtPb Nanocrystals. In ChemNanoMat, 3, 472 -478, which has been published in final form at https://doi.org/10.1002/cnma.201700069. This article may be used for non-commercial purposes in accordance with Wiley Terms and Conditions for Use of Self-Archived Versions.

\section{General Rights}

Copyright and moral rights for the publications made accessible in the public portal are retained by the authors and/or other copyright owners and it is a condition of accessing publications that users recognize and abide by the legal requirements associated with these rights.

- Users may download and print one copy of any publication from the public portal for the purpose of private study or research.

- You may not further distribute the material or use it for any profit-making activity or commercial gain

- You may freely distribute the URL identifying the publication in the public portal

If you believe that this document breaches copyright please contact us providing details, and we will remove access to the work immediately and investigate your claim.

If the document is published under a Creative Commons license, this applies instead of the general rights. 


\title{
In situ PDF study of the nucleation and growth of intermetallic PtPb nanocrystals
}

\author{
Dipankar Saha ${ }^{[a]}$, Espen D. Bøjesen ${ }^{[a]}$, Aref Hasen Mamakhel[ ${ }^{[a]}$, Martin Bremholm ${ }^{[a]}$, and Bo B. \\ Iversen*[a]
}

Dedication: This article is dedicated to Prof. T. N. Guru Row on the occasion of his $65^{\text {th }}$ birthday.

\begin{abstract}
The mechanism of Pt and PtPb nanocrystal formation under supercritical ethanol conditions has been investigated by means of in situ X-ray total scattering and pair distribution function (PDF) analysis. The metal complex structures of two different platinum precursor solutions, chloroplatinic acid and $\mathrm{Pt}(\mathrm{acac})_{2}$ (acac $=$ acetylacetonate) provide atomic-scale detail about the nucleation mechanisms after initiation of the reaction with $\mathrm{Pb}(\mathrm{acac})_{2}$ by heating. The stronger $\mathrm{Pt}-\mathrm{O}$ chemical bonding in the $\mathrm{Pt}(\mathrm{acac})_{2}$ precursor complex compared with the $\mathrm{Pt}-\mathrm{Cl}$ bonding in the chloroplatinic acid precursor complex leads to a much slower reduction of the Pt center, and this allows more optimal co-reduction conditions providing a pathway for formation of phase-pure intermetallic PtPb product. The matching chemistry of the $\mathrm{Pt}(\mathrm{acac})_{2}$ and $\mathrm{Pb}(\mathrm{acac})_{2}$ precursors allow development of a facile continuous flow supercritical ethanol process for obtaining phase-pure hexagonal PtPb nanocrystals. The study thus highlights the importance of in situ studies in revealing atomicscale information about nucleation mechanisms, which can be used in design of specific synthesis pathways, and the new continuous flow process to obtain PtPb nanocrystals holds potential for large scale production.
\end{abstract}

\section{Introduction}

There is a strong interest in developing new catalysts for electrocatalytic oxidation of small organic molecules (SOMs) such as formic acid or methanol in direct fuel cells. ${ }^{[1]}$ The development of efficient and durable catalysts for SOM oxidation is a key requirement for commercialization, and platinum and Ptbased alloys, especially $\mathrm{Pt}_{1-x} R u_{x}$, have been studied as promising candidates. ${ }^{[2]}$ However, in addition to the high cost of both $\mathrm{Pt}$ and $\mathrm{Ru}$, these catalysts suffer from major drawbacks such as poisoning on the surface by $\mathrm{CO}$ and sulfur-containing compounds, and the instability of the Pt-Ru phase reduces the catalytic activity. [2a] Current efforts include the search for alternative compounds with enhanced electrocatalytic activity and tolerance towards poisoning. PtPb has shown promising electrocatalytic activity compared with other Pt-based intermetallic compounds. ${ }^{[3]}$ Furthermore, PtPb nano-particles

[a] Dr. Dipankar Saha, Dr. Espen D. Bøjesen, Dr. Aref Hasen Mamakhel, Dr. Martin Bremholm, Prof. Dr. Bo B. Iversen Department of chemistry and iNANO

Aarhus University

140 Langelandsgade 140, DK-8000 Aarhus C, Denmark, E-mail: bo@chem.au.dk.

Supporting information for this article is given via a link at the end of the document. show enhanced activity due to increased surface area. ${ }^{[4]}$ This makes a scalable and facile synthesis strategy for production of $\mathrm{PtPb}$ nanoparticles of substantial interest.

Several reports of $\mathrm{PtPb}$ nanoparticle synthesis exist. The main difficulty relating to the synthesis of pure-phase PtPb nanoparticles is the need for simultaneous co-reduction of $\mathrm{Pt}$ and $\mathrm{Pb}$-based precursor salts. ${ }^{[5]}$ By rapid addition of a strongly reducing agent $\left(\mathrm{NaBH}_{4}\right.$ or sodium naphtalide) to metal-ion containing solutions, it has been demonstrated that co-reduction of $\mathrm{Pt}$ and $\mathrm{Pb}$-salts is indeed possible in solution. A further development of this method was a water-in-oil microemulsion technique with $\mathrm{NaBH}_{4}$ reduction. ${ }^{[5 e]}$ Another method, termed "conversion chemistry", relies on the synthesis of either supported or unsupported Pt-nanoparticles, which subsequently are mixed with a Pb-salt solution and heated in order to obtain the intermetallic $\mathrm{PtPb}$ phase. ${ }^{[5 f]}$ Collectively these studies show that the synthesis of phase-pure $\mathrm{PtPb}$ requires very strongly reducing conditions, and all studies have involved multi-step synthesis procedures, which constitute a challenge to large scale production.

Large scale synthesis of nanoparticles requires facile synthetic routes as well as scalable procedures. Continuous flow supercritical synthesis poses an advantage over the previously discussed methods, because it is a one-step process without down time, and it amenable for large scale implementation. Supercritical fluid methods utilize the unique properties of supercritical fluids, which allow tuning e.g. of solvent strength, viscosity, diffusivity, dielectric constant, ionic product and surface tension. ${ }^{[6]}$ In continuous flow reactors the supercritical fluid provide a very rapid heating at the mixing point with the precursor solution leading to high super-saturation conditions and thereby rapid nucleation of nanoparticles. ${ }^{[7]}$ The particle size, size distribution, crystallinity, and phase composition may be controlled through variation of reaction parameters such as temperature, pressure, precursor concentration, reactor residence time and choice of solvent. ${ }^{[8]}$ Reports of successful syntheses using this method are numerous, albeit most studies have concerned syntheses of metal-oxides. ${ }^{[7 a, 9]}$ Reports on the successful formation of intermetallic compounds using continuous flow supercritical processes are scarce. ${ }^{[10]}$ Alcohols have been used efficiently in supercritical synthesis as it acts both as solvent and reducing agent in supercritical condition. ${ }^{[11]}$ Supercritical alcohols not only play the role of solvent but also acts as surface modification agents which in turn effects the size of nanocrystals. ${ }^{[12]}$ Here, we combine the two concepts of rapid nucleation and a reducing supercritical solvent to develop a new method for synthesizing intermetallic PtPb nanocrystals.

Alloys and intermetallic compounds are structurally very different. In an alloy the metal atoms are randomly placed in the crystal lattice, and only metals with similar crystal structures and 
similar chemical properties will form proper alloys. Intermetallics, on the other hand, are unique substances with specific structural arrangement of metal atoms and therefore highly specific properties. In energy terms alloys have high entropy whereas intermetallics have low entropy. It is therefore often possible by heating to convert an intermetallic to an alloy, whereas the opposite is very rare. In formation of an intermetallic nanoparticle the placement of the metal atoms and their individual chemical state during the reaction needs to be much more delicately tuned than for formation of alloys. The criterium of metal co-reduction is therefore more severe for intermetallic systems than for alloys. Indeed it was indirectly found through in situ powder X-ray diffraction (PXRD) analysis of unit cell evolutions that the formation of PtRu alloy nanoparticles does not takes place through co-reduction, but through a complex multi-step mechanism. ${ }^{[13]}$ It was suggested that Pt nanoparticles are first deposited and then serve as secondary nucleation sites for $\mathrm{Ru}$. A subsequent diffusion process then leads to alloy formation. In contrast, an in situ PDF study of the formation of $\mathrm{Pt}_{3} \mathrm{Gd}$ nanoparticles reveal no peculiarities in the unit cell evolution and thus appears to support a co-reduction mechanism. ${ }^{[14]}$ The present study attempts to add further experimental evidence to the general understanding of formation of alloys and intermetallic compounds.

Total scattering (TS) and subsequent PDF analysis is gaining momentum because of its versatile applicability towards structural problems where conventional crystallographic methods have limitations. In PDF analysis Bragg diffraction and diffuse scattering are treated on equivalent terms, and this allows extraction of structural information on both crystalline and amorphous materials. ${ }^{[15]}$ With the better availability of high energy X-ray sources and strong development of analytical software for treating the TS data, PDF analysis is being applied to diverse fields of science. ${ }^{[16]}$ In this respect in situ PDF studies of nanoparticle formation under solvothermal conditions have severely challenged both classical and non-classical nucleation theories. It has been suggested that a paradigm shift is needed towards focus on the atomic scale chemistry of nucleation. ${ }^{[17]}$ In the conventional nucleation approach, one global model is assumed to fit all nucleation phenomena, but the in situ PDF analysis has revealed that in reality a diverse array of nucleation mechanism take place depending on the chemical system. ${ }^{[14,18]}$ Another recent example of the strength of the PDF technique is the experimental verification of the restructuring of solvent molecules on nanoparticle surfaces in solution. ${ }^{[19]}$ Moreover PDF analysis has been applied to determine both intra- and intermolecular correlations of organic molecules with various solvents, ${ }^{[20]}$ and also amorphous pharmaceuticals have been characterized by PDF analysis. ${ }^{[21]}$ In this study we use in situ PDF analysis to understand the formation of intermetallic PtPb nanoparticles under different experimental conditions. By exploring different starting materials and reaction conditions we obtain information that is subsequently used to design an efficient and scalable continuous flow supercritical process to synthesize phase-pure hexagonal PtPb nanocrystals.

\section{Results and Discussion}

\section{In situ synthesis}

Table 1 summarizes the in situ PDF experiments for synthesis of $\mathrm{PtPb}$ and $\mathrm{Pt}$. In the in situ experiments $\mathrm{Pt}(\mathrm{acac})_{2}$ and $\mathrm{Pb}(\mathrm{acac})_{2}$ precursors were used but in order to obtain a sufficient signal to noise ratio in the TS data, higher metal ion concentrations were necessary. Whenever $\mathrm{H}_{2} \mathrm{PtCl}_{6} \cdot 6 \mathrm{H}_{2} \mathrm{O}$ was used in the in situ reaction impurities (Table 1) were observed (supporting Information Figure S2). Previous reports emphasize that simultaneous coreduction of the platinum and the lead source is crucial if phase-pure $\mathrm{PtPb}$ is to be obtained. ${ }^{[5 \mathrm{e}]}$ Consequently, it is essential to compare the rate of the metal reduction for different precursor sources in ethanolic solutions. Previously we have shown that the formation of $\mathrm{Pt}$ nanoparticles under solvothermal condition (ethanol solvent) from $\mathrm{H}_{2} \mathrm{PtCl}_{6} \cdot 6 \mathrm{H}_{2} \mathrm{O}$ occurs via a two-step reaction mechanism. The octahedral $\mathrm{PtCl}_{6}{ }^{2-}$ complex $(\mathrm{Pt}$ is tetravalent) exists in the precursor solution and upon heating it first reduces to a square planar $\mathrm{PtCl}_{4}{ }^{2+}(\mathrm{Pt}$ is divalent) before further reduction allows formation of metallic nanoparticles. $\left.{ }^{[14}, 22\right]$ The second reduction step occurs only after the first reduction from $\mathrm{Pt}^{4+}$ to $\mathrm{Pt}^{2+}$ is completed.

Table 1. Details of different in situ total scattering experiments carried out at various temperatures. The molar ratio of $\mathrm{Pt}: \mathrm{Pb}$ was always kept at $1: 1$ and absolute ethanol was used as solvent. In all syntheses $P=250$ bar.

\begin{tabular}{lll}
\hline Temp. $\left({ }^{\circ} \mathrm{C}\right)$ & \multicolumn{1}{c}{ Precursor materials } & \multicolumn{1}{c}{$\begin{array}{r}\text { Identified product } \\
\text { phases }\end{array}$} \\
300 & $\mathrm{H}_{2} \mathrm{PtCl}_{6} \cdot 6 \mathrm{H}_{2} \mathrm{O}+\mathrm{Pb}(\text { acac })_{2}$ & $\mathrm{Pt}+\mathrm{PtPb}+\mathrm{PbPt}_{\mathrm{x}}$ \\
250 & $\mathrm{Pt}(\text { acac })_{2}+\mathrm{Pb}(\text { acac })_{2}$ & $\mathrm{PtPb}+\mathrm{PtPb}_{4}$ \\
300 & $\mathrm{Pt}(\text { acac })_{2}+\mathrm{Pb}(\mathrm{acac})_{2}$ & $\mathrm{PtPb}+\mathrm{Pt}_{3} \mathrm{~Pb}$ \\
350 & $\mathrm{Pt}(\mathrm{acac})_{2}+\mathrm{Pb}(\text { acac })_{2}$ & Pure $\mathrm{PtPb}$ \\
250 & $\mathrm{Pt}(\text { acac })_{2}$ & Pure $\mathrm{Pt}$
\end{tabular}

Here the formation of Pt nanoparticles was observed after $10 \mathrm{~s}$ of reaction in the case of $\mathrm{H}_{2} \mathrm{PtCl}_{6} \cdot 6 \mathrm{H}_{2} \mathrm{O}$ at a temperature of 250 ${ }^{\circ} \mathrm{C} .{ }^{[14]}$ For comparison we first investigated the formation of pure $\mathrm{Pt}$ nanoparticles from $\mathrm{Pt}(\mathrm{acac})_{2}$ under the same conditions. Before heating the precursor, Bragg peaks were observed on the detector due to the not fully dissolved $\mathrm{Pt}(\mathrm{acac})_{2}$ crystalline phase. However, after initiation of heating all the Bragg peaks disappeared. PDF analysis of the signal obtained from the heated solution reveals that a square planner molecular $\mathrm{Pt}\left(\mathrm{C}_{5} \mathrm{H}_{7} \mathrm{O}_{2}\right)_{2}$ complex exists in the solution (Figure $1(\mathrm{a})$ ). $\mathrm{Pt}$ is four-fold coordinated to two bidentate acetylacetonate ligands. The first peak at $1.98 \AA$ can be attributed to the Pt-O bond and other main Pt- O/C bond distances are marked in Figure $1 \mathrm{a}$. With time the area under the Pt-O peak decreases and the area under the Pt-Pt peak at $2.77 \AA$ (Figure 1(c)) increases signaling the formation of the Pt nanoparticles. 

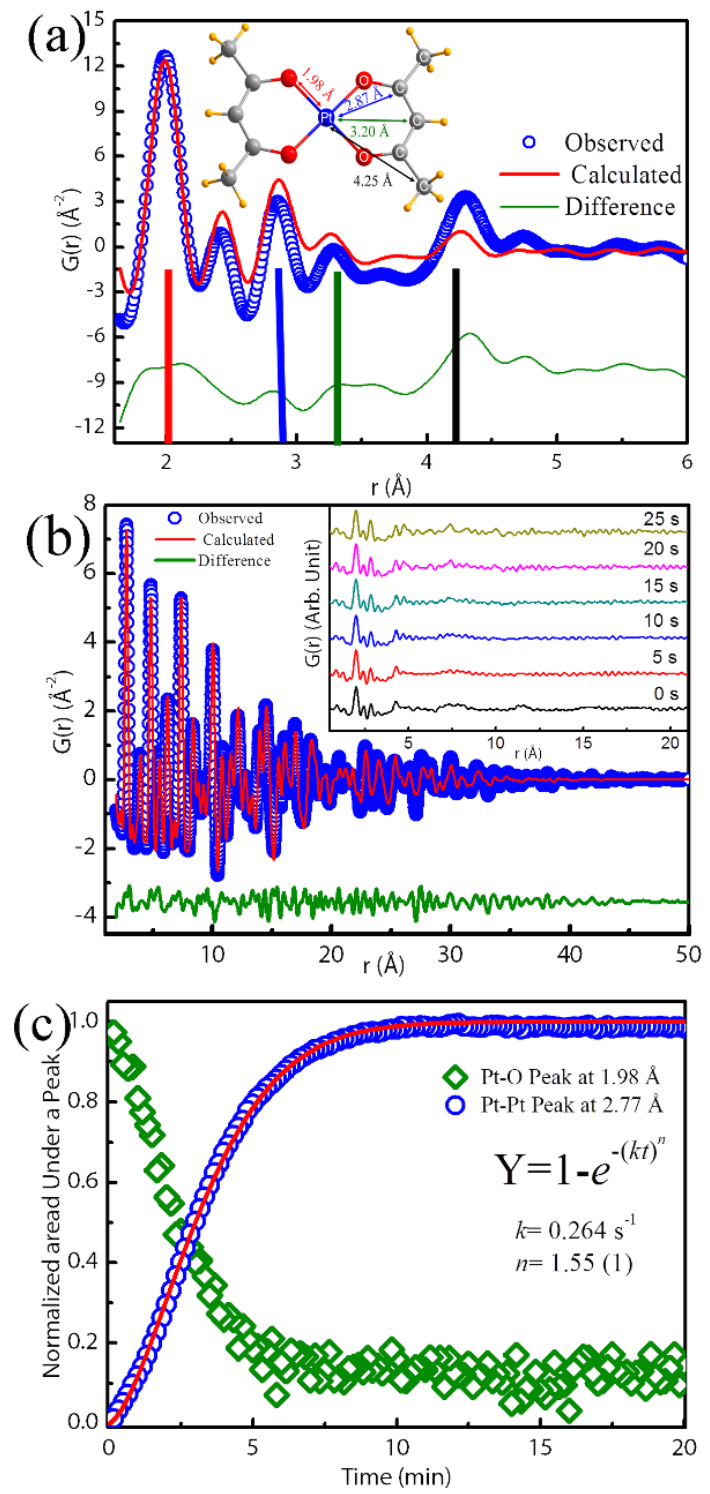

Figure 1. Synthesis of $\mathrm{Pt}$ nanoparticles using $\mathrm{Pt}(\mathrm{acac})_{2}$ as precursor. (a) Fitted PDF for square planner $\mathrm{Pt}(\mathrm{acac})_{2}$ complex (20 min after heating). First coordination Pt- O/C bond distances are marked in the figure (b) PDF refinement confirming the formation of pure Pt synthesized from $\mathrm{Pt}(\mathrm{acac})_{2}$ at $250{ }^{\circ} \mathrm{C}$ after a reaction time of $20 \mathrm{~min}\left(\mathrm{R}_{w}=0.17\right)$. Inset shows time resolved PDF of Pt synthesis. (c) Normalized peak area for the Pt-Pt bond fitted with a modified AE model (Open circle). The peak area of the Pt-O peak is shown with open squares.

The area under these two "fingerprint" peaks were normalized and plotted with respect to time in order to understand the growth mechanism. After $20 \mathrm{~min}$ of reaction the PDF could be fitted with the crystalline Pt structure (Figure 1b). Although the reaction conditions were exactly the same as in case of $\mathrm{H}_{2} \mathrm{PtCl}_{6} \cdot 6 \mathrm{H}_{2} \mathrm{O}$, the first signal from metallic Pt nanoparticles is not observed until after $25 \mathrm{sec}$ of reaction (Figure 1(c)), which is slower than the $10 \mathrm{~s}$ observed in the synthesis based on chloroplatinic acid precursor. Following the initial nucleation the $\mathrm{Pt}-\mathrm{Pt}$ signal keeps increasing, while the $\mathrm{Pt}-\mathrm{O}$ peak area is simultaneously decreasing. The Pt-Pt peak area can increase either due to smaller nanoparticles being formed or due to growth of the existing particles. No matter what the origin, a simple Avrami-Erofe'ev (AE) model, ${ }^{[23]}$ can be fitted to the Pt-Pt curve yielding $k=0.264 \mathrm{~min}^{-1}, n=1.55(1)$ (Figure 1(c)). No indication of Ostwald ripening was observed during the 20 min of the reaction as there was no rising slope of the curve of the normalized area, contrasting the synthesis based on $\mathrm{H}_{2} \mathrm{PtCl}_{6} \cdot 6 \mathrm{H}_{2} \mathrm{O}$. A similar fit to the Pt-Pt peak area in the case of $\mathrm{H}_{2} \mathrm{PtCl}_{6} \cdot 6 \mathrm{H}_{2} \mathrm{O}$ gave $k=2.43 \times 10^{-2} \mathrm{~s}^{-1}, n=4.3, k_{\mathrm{OR}}=5.4 \times 10^{-3} \mathrm{~s}^{-1}$ and $t_{\mathrm{OR}}=40 \mathrm{~s}$ where Ostwald ripening occurs. ${ }^{[14]}$ In fact in this case all initial precursor is used up after only $\sim 90 \mathrm{sec}$, whereas it takes $\sim 5$ minutes in the case of $\mathrm{Pt}(\mathrm{acac})_{2}$. The differences in the increase of the Pt-Pt peak area indicates that the reduction of $\mathrm{Pt}^{2+}$ to $\mathrm{Pt}$ is much slower for $\mathrm{Pt}(\mathrm{acac})_{2}$ than in the case of $\mathrm{H}_{2} \mathrm{PtCl}_{6} \cdot 6 \mathrm{H}_{2} \mathrm{O}$. It should be noted that the reduction potential $(0.743 \mathrm{~V})$ of $\left[\mathrm{PtCl}_{6}\right]^{2-}$ to $\mathrm{Pt}(\mathrm{s})$ is much higher than reduction potential $(-1.7 \mathrm{~V})$ of $\mathrm{Pt}(\mathrm{acac})_{2}$ to $\mathrm{Pt}(\mathrm{s}) .^{[24]}$ Therefore, it may be argued that reducing chloroplatinic acid should be much easier than $\mathrm{Pt}(\mathrm{acac})_{2}$. This indicates that the formation of $\mathrm{Pt}$ impurities during $\mathrm{PtPb}$ synthesis with chloroplatinic acid may be attributed to a too fast reduction of octahedral $\mathrm{PtCl}_{6}{ }^{2-}$. In combination this suggests that the initial period of the reaction is crucial for the product formation as the reduction process occurs during this period and the rate of the reduction process controls the final product composition. Since the rate of the reduction process depends on the nature of the precursor complex different $\mathrm{Pt}$ sources were investigated.

Peak area analysis of the peaks corresponding to Pt-O (1.98 $\AA)$ and $\mathrm{Pb}-\mathrm{O}(2.37 \AA)$ shows a comparable reduction rate of $\mathrm{Pt}(\mathrm{acac})_{2}$ and $\mathrm{Pb}(\mathrm{acac})_{2}$ within $20 \mathrm{~s}$ of the reaction (Figure 2(b)). This suggests that the reduction rates for both the starting materials are comparable. After $20 \mathrm{sec}$. of reaction new peaks appear in the PDF due to the formation of PtPb nanoparticles which grow with increasing reaction time (Figure 2(a)). The size of the PtPb nanoparticles were found to be $\sim 7 \mathrm{~nm}$ after PDF refinement, which is in agreement with the PXRD Rietveld refinement. Fitting of PDF peaks in order to find growth kinetics of $\mathrm{PtPb}$ was unsuccessful since the peaks of $\mathrm{PtPb}$ were overlapped with many peaks, corresponding to precursor. Therefore, the growth curve for PtPb nanoparticles was fitted with a kinetic model by analyzing the particle size obtained after PDF refinement.

A modified $A E$ equation was introduced to fit the data since a simple $A E$ model was unable to fit the rising slope at the later time of the reaction. ${ }^{[23,25]}$ Figure 3 shows that modified $A E$ model provides an excellent fit to normalized data giving the parameters $k=0.49 \mathrm{~min}^{-1}, n=0.44, k_{\mathrm{OR}}=1.32 \times 10^{-3} \mathrm{~s}^{-1}$ and $t_{\mathrm{OR}}=$ $11.3 \mathrm{~min}$. In the case of bulk nucleation mechanisms for solidstate reactions the $n$ parameter is normally larger than 1 , whereas is approaches 1 for surface nucleation mechanisms. Solvothermal formation conditions are not the same as a solidstate transformations, but even so the $A E$ equation is often used to analyze the kinetics of such processes. 

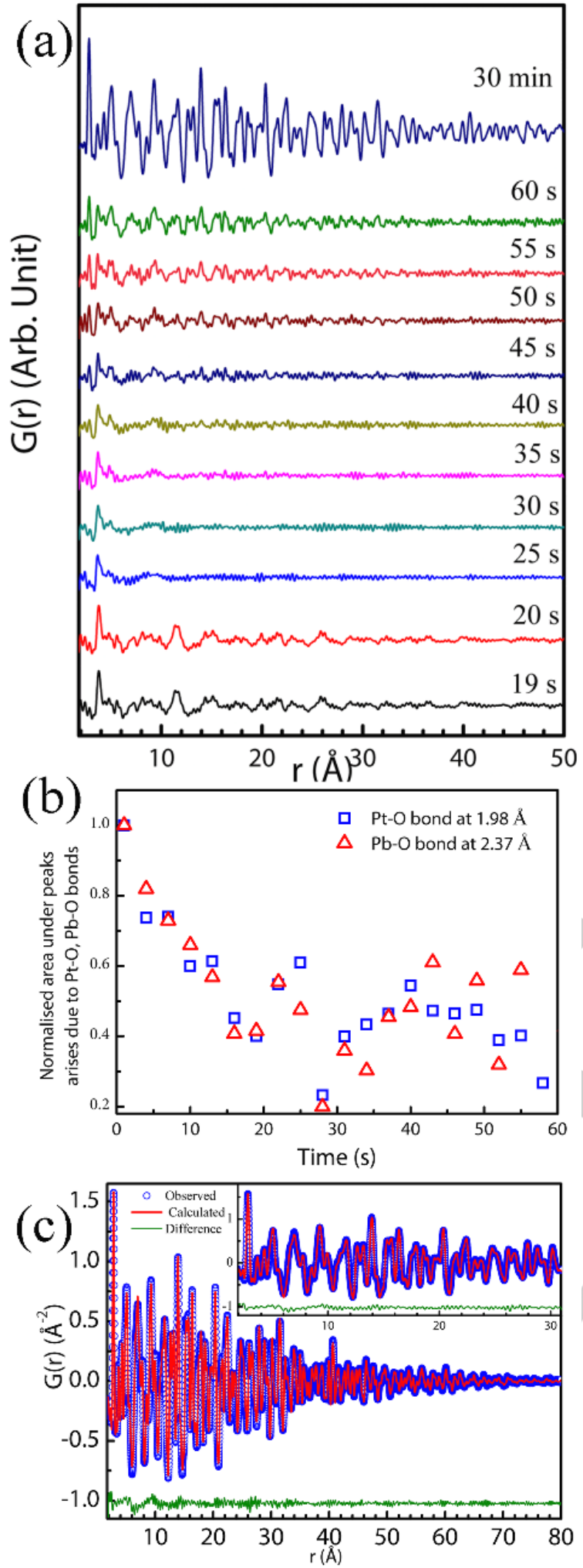

The value of $\mathrm{k}=0.264 \mathrm{~min}^{-1}$ and $\mathrm{n}=1.55$ for $\mathrm{Pt}(\mathrm{acac}) 2$ were obtained after fitting the Avrami-Erofe'ev (AE) model, whereas the values of $\mathrm{k}$ and $\mathrm{n}$ were $0.49 \mathrm{~min}^{-1}$ and 0.44 for PtPb. Thus, it is clear from the rate constant that the rate is faster in case of $\mathrm{PtPb}$. As seen above the growth of Pt nanoparticles have $n>1$ ( $n=4.3$ for platinic acid and $n=1.55$ for $\mathrm{Pt}(\mathrm{acac})_{2}$ ) indicating inhomogeneous distribution of nuclei ${ }^{[26]}$ and showing that in this case the supercritical ethanol solvent has limited impeding effects. It is, however, conspicuous that $n$ is much smaller than unity in the case of PtPb nanocrystal growth $(n=0.44)$. Thus, $\mathrm{PtPb}$ formation is far from a bulk solid state reaction and presumable considerable structural rearrangements are necessary with significant influences from the surrounding solvent system.

Since the standard reduction potentials of pure $\mathrm{Pb}$ and $\mathrm{Pt}$ are $-0.13 \mathrm{~V}$ and $+1.3 \mathrm{~V}$, respectively, ${ }^{[27]} \mathrm{Pt}$ is more easily and rapidly reduced than $\mathrm{Pb}$. Therefore, instead of the ordered intermetallic compound $\mathrm{PtPb}$, only $\mathrm{Pt}$ or $\mathrm{Pb}$ nanoparticles would be formed by selective reduction of the metals as confirmed by in situ measurements. If a two step reduction takes place then $\mathrm{Pt}$ is first reduced and then secondly $\mathrm{Pb}$ producing a multiphase mixture of nanoparticles, or perhaps core-shell morphologies. Another possibility is the alloy formation which is observed in case of PtRu nanoparticles where initially formed Pt cluster nanocrystals act as a nucleation point for $\mathrm{Ru}$, and the alloy forms by diffusion of $\mathrm{Ru}$ in $\mathrm{Pt}$ matrix. ${ }^{[13]}$ Co-reduction of the metals is crucial for formation of ordered PtPb intermetallics, and here it was achieved by selecting the correct precursor materials unlike previous syntheses where co-reduction of the metals was achieved by addition of a very strong reducing agent. ${ }^{[5]}$

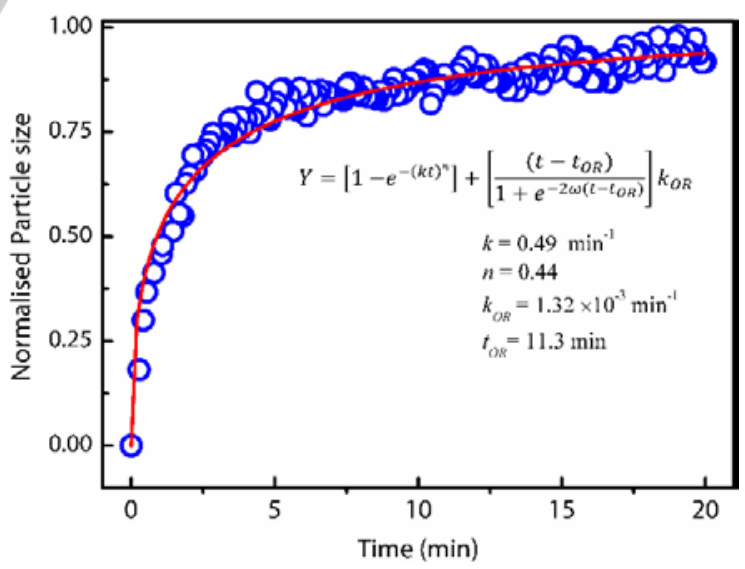

Figure 3. Rate curve for $\mathrm{PtPb}$ growth. The first term in the equation corresponds to the nucleation and aggregative particle growth, while the second term accounts for Ostwald ripening. At a given time $\mathrm{t}, k$ is the rate parameter for the nucleation, $n$ is dimensionality of the reaction. $t_{\mathrm{OR}}$ and $k_{O R}$ are the time of the onset of Ostwald ripening and a rate parameter. The start of the heating was set to zero seconds for the fitting of the data. 

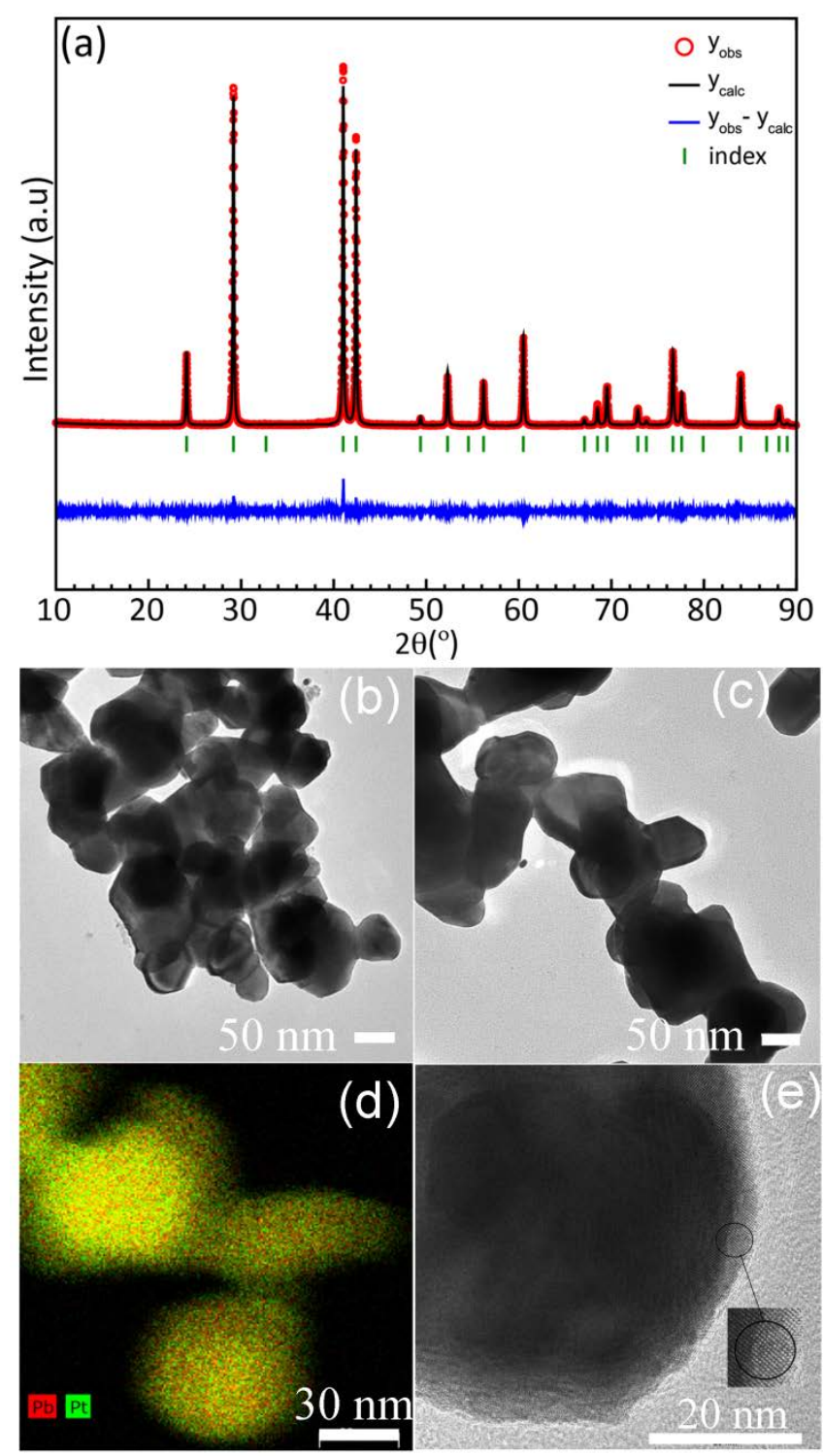

Figure 4. (a) Rietveld refinement of PXRD data of PtPb synthesized in the flow reactor at $300{ }^{\circ} \mathrm{C}$. (b-d) TEM micrographs and STEMEDX analysis showing facetted $\mathrm{PtPb}$ nanoparticles with homogenously distributed $\mathrm{Pt}$ and $\mathrm{Pb}$ and (e) HRTEM micrograph of $\mathrm{PtPb}$ nanoparticle.

\section{Flow synthesis of phase pure PtPb}

The in situ PDF data discussed above suggest a possible route to synthesize phase pure $\mathrm{PtPb}$ using $\mathrm{Pt}(\mathrm{acac})_{2}$ and $\mathrm{Pb}(\mathrm{acac})_{2}$ with a 1:1 molar ratio as starting materials. Indeed, phase-pure hexagonal $\mathrm{PtPb}$ nanoparticles can be obtained at temperatures of $250{ }^{\circ} \mathrm{C}$ and $300{ }^{\circ} \mathrm{C}$ in the continuous flow reactor. Figure 4 shows a Rietveld refinement of the diffraction pattern collected for $\mathrm{PtPb}$ synthesized at $300{ }^{\circ} \mathrm{C}$ (details are given in the supplementary information). The average $\mathrm{PtPb}$ crystallite size was found to be $45(1) \mathrm{nm}$ for a synthesis temperature of $300^{\circ} \mathrm{C}$, whereas an average particles size of 34(1) nm was obtained at
$250{ }^{\circ} \mathrm{C}$. Figure 4 also shows TEM images recorded on the PtPb nanoparticles synthesized at $300^{\circ} \mathrm{C}$ as well as an overlay of the elemental distribution maps obtained from STEM-EDS on a selection of particles. It is clearly seen that the PtPb nanoparticles are well crystallized, and many particles are partially faceted with no particular defect features visible in the HR-TEM images. Furthermore, both $\mathrm{Pt}$ and $\mathrm{Pb}$ are distributed evenly throughout the particles. The particle sizes observed by TEM are in good agreement with the crystallite sizes obtained from Rietveld refinement. The present synthesis route opens up the possibility of synthesizing pure PtPb hexagonal phase in large quantities, which is essential for industrial application of nanoparticles.

\section{Conclusions}

Synthesis of phase pure intermetallic nanoparticles requires strong control of the reaction conditions in order to obtain simultaneous co-reduction of the metals and avoid impurity formation. Total scattering analysis reveals that for a $\mathrm{Pt}(\mathrm{acac})_{2}$ precursor $\mathrm{Pt}$ exists as square planner complex in solution, coordinated by two acetylacetonate ligand. PDF analysis was also used to estimate the reduction rates of different $\mathrm{Pt}$ precursors, and suitable co-reduction conditions were found to be achievable only for $\mathrm{Pt}(\mathrm{acac})_{2}$ and $\mathrm{Pb}(\mathrm{acac})_{2}$ precursors in supercritical ethanol. Modelling of the crystal growth kinetics using an $A E$ model shows that formation of pure $\mathrm{Pt}$ nanoparticles with different precursor solutions have $n>1$, which is similar to bulk solid state reactions. In contrast the formation of $\mathrm{PtPb}$ has $n \sim 0.4$ suggesting that substantial structural rearrangement is taking place leading to impeding effects of the surrounding solvent. The in situ reaction conditions were subsequently transferred to synthesis in a continuous flow supercritical reactor, and phase pure $\mathrm{PtPb}$ nanocrystals with a size of $34 \mathrm{~nm}\left(T=250{ }^{\circ} \mathrm{C}\right)$ and $45 \mathrm{~nm}\left(\mathrm{~T}=300^{\circ} \mathrm{C}\right)$ were obtained. The highly efficient process uses supercritical ethanol both as solvent and metal reductant, and it holds promise for large scale production of nanoscale catalysts e.g. for electrocatalytic oxidation of small organic molecules in fuel cells.

\section{Experimental Section}

\section{Chemicals}

The following reagents were used as purchased: $\mathrm{H}_{2} \mathrm{PtCl}_{6} \cdot 6 \mathrm{H}_{2} \mathrm{O}$ (Strem Chemicals, 78-0200), $\mathrm{Pt}\left(\mathrm{C}_{5} \mathrm{H}_{7} \mathrm{O}_{2}\right)_{2}$ (Sigma Aldrich, 4136189)), and $\mathrm{Pb}\left(\mathrm{C}_{5} \mathrm{H}_{7} \mathrm{O}_{2}\right)_{2}$ (Sigma Aldrich, 401684), Absolute ethanol (Sigma Aldrich, 02865).

\section{Supercritical flow synthesis}

The continuous flow synthesis was carried out using a modular supercritical flow reactor developed at Aarhus University. ${ }^{[8 c]}$ The details of the reactor and synthesis condition are included in the supporting information. 


\section{Total scattering experiment}

In situ total $\mathrm{X}$-ray scattering experiments were carried out at beam line P02.01 at PETRA III, DESY, Germany, using a wavelength of $0.207 \AA$ $(59.9 \mathrm{keV}){ }^{[28]}$ For the synthesis of intermetallic $\mathrm{PtPb}$, two different types of $\mathrm{Pt}$ precursors, $\mathrm{H}_{2} \mathrm{PtCl}_{6} \cdot 6 \mathrm{H}_{2} \mathrm{O}$ and $\mathrm{Pt}\left(\mathrm{C}_{5} \mathrm{H}_{7} \mathrm{O}_{2}\right)_{2}$ were used. The concentration of the solution was kept at $0.5 \mathrm{M}$. The molar ratio was 1:1 for all the intermetallic synthesis. For Pt synthesis only $\mathrm{Pt}\left(\mathrm{C}_{5} \mathrm{H}_{7} \mathrm{O}_{2}\right)_{2}$ was dissolved in ethanol $(0.5 \mathrm{M})$. Clear precursor solutions were used for the in situ experiments in a custom-made capillary reactor. ${ }^{[29]}$ The syntheses were performed by loading the precursor into a $0.6 / 0.7$ (inner/outer) $\mathrm{mm}$ diameter fused silica capillary. The capillary was pressurized to 250 bar by a LabAlliance HPLC pump using water (99\%) as the pressurizing medium. Afterwards, the capillary was heated to set temperatures by a hot air jet with temperature measured by a K-type thermocouple. Due to the small volume of the capillary and the efficiency of the heater, $90 \%$ of the set-temperature was reached within the first 10 seconds of heating. Concurrent with initiation of the heating, scattering from a monochromatic $X$-ray beam $(\lambda=0.207 \AA$ ) was recorded by a fast area detector, Perkin Elmer XRD1621. The sample-to-detector distance was $194 \mathrm{~mm}$. Detector frames were read out continuously, giving an effective time resolution of 1 second. The center heating of the capillary creates a density plug of heavy solvent in the ends, which keeps the growing particles in the X-ray beam under well defined thermodynamic conditions. During the experiment it has been found that the actual temperatures are $10 \%$ lower than the set temperatures. ${ }^{[30]}$ The FIT2D software ${ }^{[31]}$ was used to integrate the 2D data sets. Prior to integration, the X-ray wavelength was calibrated. The detector geometry, such as distance from the sample and obliquity, was then determined using a $\mathrm{LaB}_{6}$ (NIST) sample. The integrated total scattering data were analyzed with the PDFgetX3 program. ${ }^{[32]}$ Prior to the Fourier transformation, the data were corrected for background scattering using measurements of ethanol in the same capillary at appropriate temperatures. Structure functions were used up to a $Q_{\max }$ of $17.5 \AA^{-1}$, where the $Q$-range was limited from the theoretical maximum in this case by signal to noise issues after subtracting the background. The resulting PDFs were refined using PDFgui. ${ }^{[33]}$ Rietveld refinements were carried out using the FullProf suite. ${ }^{[34]}$

\section{Characterization}

The flow synthesis products were collected as black suspensions which were allowed to dry in air and characterized with PXRD. The PXRD data were measured on a Rigaku Smart Lab powder diffractometer with Bragg-Brentano geometry. A Ge(111) single crystal monochromator was used to produce $\mathrm{Cu} \mathrm{Ka}_{1}$ radiation. HR-TEM, STEM and STEM-EDS data were obtained on a TALOS F200A with a TWIN lens system, X-FEG electron source, Ceta 16M Camera and a Super-X EDS Detector. Spatially resolved elemental analysis, was obtained using the same TALOS microscope in STEM mode. Exposure times of 8 minutes were used to create elemental distribution maps with satisfactory counting statistics, while minimizing potential problems such as beam damage and specimen drift. STEM pictures were obtained using a High Angle Annular Dark Field detector (HAADF). A drop of a sonicated ethanolic nanoparticle suspension was deposited on a holey carbon film on copper grid and allowed to dry at ambient conditions.

\section{Acknowledgements}

The work was supported by the Danish National Research Foundation (Center for Materials Crystallography, DNRF93). We thank DESY, Germany, a member of the Helmholtz Association (HGF), for beamtime.
Keywords: Pair Distribution Function - nanoparticleintermetallic, continuous flow synthesis, supercritical ethanol

[1] aC. Lamy, A. Lima, V. LeRhun, F. Delime, C. Coutanceau, J.-M. Léger J. Power Sources 2002, 105, 283-296; bB. D. McNicol, D. A. J. Rand, K. R. Williams, J. Power Sources 2001, 100, 47-59; cC. Rice, S. Ha, R. I. Masel, P. Waszczuk, A. Wieckowski, T. Barnard, J. Power Sources 2002, 111, 83-89.

[2] aJ.-M. Léger, J. Appl. Electrochem. 2001, 31, 767-771; bM. Watanabe, M. Uchida, S. Motoo, J. Electroanal. Chem. Interfacial Electrochem. 1987, 229, 395-406; cJ. W. Long, R. M. Stroud, K. E. Swider-Lyons, D. R. Rolison, J. Phys. Chem. B 2000, 104, 9772-9776; dX. Ren, P. Zelenay, S. Thomas, J. Davey, S. Gottesfeld, J. Power Sources 2000, 86, 111-116.

[3] E. Casado-Rivera, D. J. Volpe, L. Alden, C. Lind, C. Downie, T. Vázquez-Alvarez, A. C. D. Angelo, F. J. DiSalvo, H. D. Abruña, J. Am. Chem. Soc. 2004, 126, 4043-4049.

[4] C. Roychowdhury, F. Matsumoto, V. B. Zeldovich, S. C. Warren, P. F. Mutolo, M. Ballesteros, U. Wiesner, H. D. Abruña, F. J. DiSalvo, Chem. Mater. 2006, 18, 3365-3372

[5] aL. R. Alden, C. Roychowdhury, F. Matsumoto, D. K. Han, V. B. Zeldovich, H. D. Abruña, F. J. DiSalvo, Langmuir 2006, 22, 10465-10471; bL. R. Alden, D. K. Han, F. Matsumoto, H. D. Abruña, F. J. DiSalvo, Chem. Mater 2006, 18, 5591-5596; cC. Roychowdhury, F. Matsumoto, P. F. Mutolo, H. D. Abruña, F. J. DiSalvo, Chem. Mater. 2005, 17, 5871-5876; dT. Ghosh, F. Matsumoto, J. McInnis, M. Weiss, H. D. Abruña, F. J. DiSalvo, J. Nanopart Res. 2009, 11, 965-980; eL. M. Magno, W. Sigle, P. A. van Aken, D. G. Angelescu, C. Stubenrauch, Chem. Mater. 2010, 22, 6263-6271; fJ. C. Bauer X. Chen, Q. Liu, T.-H. Phan, R. E. Schaak, J. Mater. Chem. 2008, 18, 275 282; gR. E. Cable, R. E. Schaak, Chem. Mater. 2005, 17, 6835-6841.

[6] aE. Reverchon, R. Adami, J. Supercrit. Fluids 2006, 37, 1-22; bT. Adschiri, K. Kanazawa, K. Arai, J. Am. Ceram. Soc. 1992, 75, 1019-1022.

[7] aC. Aymonier, A. Loppinet-Serani, H. Reverón, Y. Garrabos, F. Cansell, J. Supercrit. Fluids 2006, 38, 242-251; bE. Lester, P. Blood, J. Denyer, D. Giddings, B. Azzopardi, M. Poliakoff, J. Supercrit. Fluids 2006, 37, 209-214 cT. Adschiri, Y. Hakuta, K. Sue, K. Arai, J. Nanopart. Res. 2001, 3, 227-235.

[8] aP. Hald, J. Becker, M. Bremholm, J. S. Pedersen, J. Chevallier, S. B Iversen, B. B. Iversen, J. Solid State Chem. 2006, 179, 2674-2680; bL. L. Toft D. F. Aarup, M. Bremholm, P. Hald, B. B. Iversen, J. Solid State Chem. 2009, 182, 491-495; cJ. Becker, P. Hald, M. Bremholm, J. S. Pedersen, J. Chevallier, S. B. Iversen, B. B. Iversen, ACS Nano 2008, 2, 1058-1068.

[9] aK. Sue, M. Suzuki, K. Arai, T. Ohashi, H. Ura, K. Matsui, Y. Hakuta, H. Hayashi, M. Watanabe, T. Hiaki, Green Chem. 2006, 8, 634-638; bH. Reverón, C. Elissalde, C. Aymonier, O. Bidault, M. Maglione, F. Cansell, J. Nanosci. Nanotechnol. 2005, 5, 1741-1744; cW. E Stallings, H. H. Lamb, Langmuir 2003, 19, 2989-2994; dA. Cabanas, M. Poliakoff, J. Mater. Chem. 2001, 11 1408-1416; eG. Philippot, K. M. Ø. Jensen, M. Christensen, C. Elissalde, M. Maglione, B. B. Iversen, C. Aymonier, J. Supercrit. Fluids 2014, 87, 111-117; fF. Cansell, C. Aymonier, J. Supercrit. Fluids 2009, 47, 508-516.

[10] aJ.-L. Mi, M. Christensen, C. Tyrsted, K. M. Ø. Jensen, J. Becker, P. Hald, B. B. Iversen, J. Phys. Chem. C 2010, 114, 12133-12138; bJ.-L. Mi, T. N. Jensen, P. Hald, J. Overgaard, M. Christensen, B. B. Iversen, J. Supercrit Fluids 2012, 67, 84-88.

[11] aJ. Kim, D. Kim, B. Veriansyah, J. Won Kang, J.-D. Kim, Mater. Lett. 2009, 63, 1880-1882; bC. Morin, A. Loppinet-Serani, F. Cansell, C. Aymonier J. Supercrit. Fluids 2012, 66, 232-240; cC. Slostowski, S. Marre, O. Babot, T. Toupance, C. Aymonier, Langmuir 2014, 30, 5965-5972.

[12] C. Slostowski, S. Marre, O. Babot, T. Toupance, C. Aymonier, Langmuir 2012, 28, 16656-16663.

[13] J.-L. Mi, P. Norby, M. Bremholm, J. Becker, B. B. Iversen, Nanoscale 2015, 7, 16170-16174.

[14] D. Saha, E. D. Bøjesen, K. M. Ø. Jensen, A.-C. Dippel, B. B. Iversen, J. Phys. Chem. C 2015, 119, 13357-13362.

[15] aT. Egami, S. J. Billinge, Underneath the Bragg Peaks: Structural Analysis of Complex Materials, Vol. 16, Pergamon, 2012; bS. J. L. Billinge, M. G. Kanatzidis, Chem. Commun. (Cambridge, U. K.) 2004, 749-760.

[16] C. A. Young, A. L. Goodwin, J. Mater. Chem. 2011, 21, 6464-6476.

[17] E. D. Bojesen, K. M. O. Jensen, C. Tyrsted, A. Mamakhel, H. L. Andersen, H. Reardon, J. Chevalier, A.-C. Dippel, B. B. Iversen, Chemical Science 2016

[18] aK. M. Ø. Jensen, M. Christensen, P. Juhas, C. Tyrsted, E. D. Bøjesen, N. Lock, S. J. L. Billinge, B. B. Iversen, J. Am. Chem. Soc. 2012, 134, 6785$6792 ;$ bC. Tyrsted, K. M. Ø. Jensen, E. D. Bøjesen, N. Lock, M. Christensen, S. J. L. Billinge, B. B. Iversen, Angew. Chem., Int. Ed. 2012, 51, 9030-9033 cD. Saha, K. M. Ø. Jensen, C. Tyrsted, E. D. Bøjesen, A. H. Mamakhel, A.-C. Dippel, M. Christensen, B. B. Iversen, Angew. Chem. Int Ed. 2014, 53, 3667 3670; dC. Tyrsted, N. Lock, K. M. O. Jensen, M. Christensen, E. D. Bojesen, $\mathrm{H}$. Emerich, G. Vaughan, S. J. L. Billinge, B. B. Iversen, IUCrJ 2014, 1, 165 171 ; eK. M. $\varnothing$. Jensen, H. L. Andersen, C. Tyrsted, E. D. Bøjesen, A.-C. Dippel, N. Lock, S. J. L. Billinge, B. B. Iversen, M. Christensen, ACS Nano 
2014, 8, 10704-10714; fJ.-L. Mi, K. M. O. Jensen, C. Tyrsted, M. Bremholm, B. B. Iversen, CrystEngComm 2015, 17, 6868-6877.

[19] M. Zobel, R. B. Neder, S. A. J. Kimber, Science 2015, 347, 292-294.

[20] D. Prill, P. Juhás, M. U. Schmidt, S. J. L. Billinge, J. Appl. Crystallogr. 2015, 48, 171-178.

[21] aS. J. L. Billinge, T. Dykhne, P. Juhas, E. Bozin, R. Taylor, A. J. Florence, K. Shankland, CrystEngComm 2010, 12, 1366-1368; bT. Dykhne, R. Taylor, A. Florence, S. L. Billinge, Pharm. Res. 2011, 28, 1041-1048.

[22] A.-C. Dippel, N. Bindzus, D. Saha, J. T. Delitz, H.-P. Liermann, N. Wahlberg, J. Becker, E. D. Bøjesen, B. Brummerstedt Iversen, Z. Anorg. Allg Chem. 2014, 640, 3094-3099.

[23] M. Avrami, J. Chem. Phys. 1939, 7, 1103-1112.

[24] aY. Li, Y. Jiang, M. Chen, H. Liao, R. Huang, Z. Zhou, N. Tian, S. Chen S. Sun, Chem. Commun. (Cambridge, U. K.) 2012, 48, 9531-9533; bS. Sultana, N. Tachikawa, K. Yoshii, L. Magagnin, K. Toshima, Y. Katayama, J. Electrochem. Soc. 2016, 163, D401-D406.

[25] aM. Avrami, J. Chem. Phys. 1940, 8, 212-224; bM. Avrami, J. Chem Phys. 1941, 9, 177-184; cS. P. Shields, V. N. Richards, W. E. Buhro, Chem. Mater. 2010, 22, 3212-3225; dV. N. Richards, N. P. Rath, W. E. Buhro, Chem. Mater. 2010, 22, 3556-3567; eV. N. Richards, S. P. Shields, W. E. Buhro, Chem. Mater. 2011, 23, 137-144.

[26] N. Sun, X. Liu, K. Lu, Scr. Mater. 1996, 34, 1201-1207.
[27] R. C. Weast, D. Lide, M. Astle, W. Beyer, Handbook of Chemistry and Physics. -1989-1990, Boca Raton: CRC Press, 1989.

[28] A.-C. Dippel, H.-P. Liermann, J. T. Delitz, P. Walter, H. SchulteSchrepping, O. H. Seeck, H. Franz, J. Synchrotron Rad. 2015, 22, 675-687. [29] J. Becker, M. Bremholm, C. Tyrsted, B. Pauw, K. M. O. Jensen, J. Eltzholt, M. Christensen, B. B. Iversen, J. Appl. Crystallogr. 2010, 43, 729-736.

[30] P. J. Chupas, K. W. Chapman, C. Kurtz, J. C. Hanson, P. L. Lee, C. P. Grey, J. Appl. Crystallogr. 2008, 41, 822-824.

[31] A. Hammersley, S. Svensson, M. Hanfland, A. Fitch, D. Hausermann Int. J. High Pressure Res. 1996, 14, 235-248.

[32] P. Juhas, T. Davis, C. L. Farrow, S. J. L. Billinge, J. Appl. Crystallogr. 2013, 46, 560-566.

[33] C. L. Farrow, P. Juhas, J. W. Liu, D. Bryndin, E. S. Božin1, J. Bloch, T. Proffen, S. J. L. Billinge, J. Phys.: Condens. Matter 2007, 19, 335219-335226.

[34] J. Rodríguez-Carvajal, Physica B 1993, 192, 55-69. 


\section{FULL PAPER}
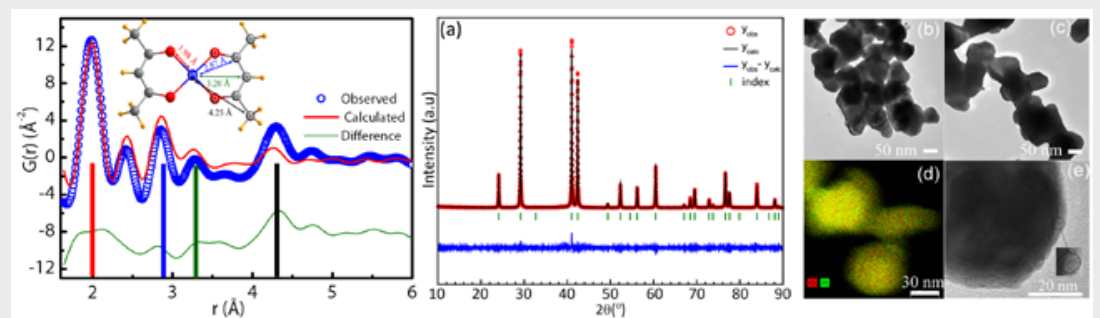

Dipankar Saha, Espen D. Bøjesen], Aref Hasen Mamakhel, Martin Bremholm, and Bo B. Iversen*

In situ PDF study of the nucleation and growth of intermetallic $\mathrm{PtPb}$ nanocrystals

In situ total scattering studies provide a deeper understanding of the nucleation mechanism kinetics of Pt nanoparticle formation, and allow structural modelling of the precursor structure. The similar reaction kinetics of $\mathrm{Pt}(\mathrm{acac})_{2} \mathrm{and} \mathrm{Pb}(\mathrm{acac})_{2}$ precursors lead to development of a facile continuous flow supercritical ethanol process for obtaining phase pure hexagonal $\mathrm{PtPb}$ nanocrystals. 